Fourth International Symposium on Physics of Fluids (ISPF4)

International Journal of Modern Physics: Conference Series

Vol. 19 (2012) 276-282

(C) World Scientific Publishing Company

DOI: $10.1142 / \mathrm{S} 2010194512008860$

\title{
AERODYNAMIC ANALYSIS OF A ROLLING WRAPAROUND FIN PROJECTILE IN SUPERSONIC FLOW
}

\author{
JUNG-YOUNG KIM, SUNG-IN CHO AND IN LEE \\ Department of Aerospace Engineering, School of Mechanical Aerospace and System Engineering, \\ Korea Advanced Institute of Science and Technology (KAIST), Korea \\ Inlee@kaist.ac.kr \\ HYOUNG-JIN NA AND SANG-YOUNG JUNG
}

Department of PGM technology, Hanwha Co., Korea

\begin{abstract}
In this paper, the roll characteristics of a rolling wraparound fin projectile have been investigated in supersonic region. Computation of the flowfield was performed using a time-marching, threedimensional Euler equation in a body fixed rotating coordinate frame. First, the roll producing moment coefficients of a projectile were obtained from the flowfiled solution at various Mach numbers and compared with the experimental and numerical results. They showed favorable agreement with experimental results in magnitude and sign. Next, the roll damping moment coefficients of a rolling wraparound fin were computed and compared with correlation based on experiment data. The correlation gave a somewhat larger value in magnitude than the present computation. However, the computed values agreed well with correlation in the trend.
\end{abstract}

Keywords: Wraparound fin; roll moment; 3D Euler equation.

\section{Introduction}

Wraparound fins, which are curved along the spanwise direction, have been used primarily for their advantages in packaging tube-launched projectiles for several decades. They can be folded to fit in the cylindrical body in the launch tube, so a more efficient use of space is available. Thus, greater number of wraparound fin projectiles can be stored in the same space as fixed fin projectiles designed to deliver the same payload. ${ }^{1-3}$ Wraparound fins, because of their asymmetric and cylindrical shapes, have unusual lateral aerodynamic characteristics. They can produce rolling moment even at zero angle of attack. In addition, the roll moment coefficient may change in magnitude and sign as Mach number varies ${ }^{2,3}$. During the flight of a wraparound fin projectile, its roll rate may increase or decrease more than once and can change rolling direction.

The accurate prediction of the roll characteristics of projectiles is important in projectile designs. Well-designed projectiles will have an equilibrium roll rate that avoids both the yawing frequency and their first natural frequency of vibration. The yawing frequency is avoided to preclude the possibility of roll/yaw lock in, which may lead to increase in yaw during the flight. If the flight body experiences roll rate near the first 
natural frequency, severe bending of the body may occur. Typically, the first natural frequency and the yawing frequency represent an upper and lower bound for the design equilibrium roll rate $^{4}$.

The roll behavior of a projectile can be characterized by the roll producing moment coefficient, the roll damping moment coefficient, and the equilibrium spin rate ${ }^{4,5}$. The roll producing moment coefficient is defined as the roll moment coefficient produced in the absence of roll rate, at zero angle of attack. The roll damping moment coefficient is defined as the roll moment coefficient derivative with respect to nondimensionalized roll rate. The equilibrium roll rate is defined as the roll rate for which the net roll moment is zero.

There are not many numerical studies on the roll characteristics for wraparound fins. Only the roll producing moment coefficient had been determined for nonaxisymmetric bodies using Euler and Navier-Stokes computational codes ${ }^{4,6}$. Projectile designers relied on approximate methods ${ }^{7}$ to determine the roll damping moment coefficient or the steady state roll rate. Weinacht and Sturek ${ }^{4}$ applied a computational method based on the parabolized Navier-Stokes equations to determine the roll producing moment coefficient, the roll damping moment coefficient and the equilibrium roll rate of a nonaxisymmetric body. Recently, Paek and Lee ${ }^{5}$ performed computation using a time-marching, threedimensional Euler equation in a body fixed rotating coordinate frame. Roll damping moment coefficients for the rigid as well as flexible fins were obtained and compared with Mikhail's correlation.

In this paper, the aerodynamic force was computed by solving the Euler equations. The governing equations were appropriately modified to include the Coriolis and centrifugal accelerations resulting from the body fixed rotating coordinate frame. This computational approach was applied to predict the roll producing and roll damping moment coefficients and the steady state roll rate in supersonic range.

\section{Aerodynamic model}

The Euler equations of a strong conservative form in a generalized coordinate system are given as ${ }^{4,5}$

$$
\frac{\partial \hat{Q}}{\partial t}+\frac{\partial \hat{F}}{\partial x}+\frac{\partial \hat{G}}{\partial y}+\frac{\partial \hat{H}}{\partial z}=\hat{S},
$$

where the conservation variable vector $\hat{Q}$, the flux vectors $\hat{F}, \hat{G}$ and $\hat{H}$, and the source vector $\hat{S}$ are written as

$$
\begin{gathered}
\hat{Q}=J^{-1}\left[\begin{array}{lllll}
\rho & \rho u & \rho v & \rho w & \rho e
\end{array}\right]^{T}, \\
\hat{F}=J^{-1}\left[\begin{array}{lllll}
\rho U & \rho u U+\xi_{x} p & \rho v U+\xi_{y} p & \rho w U+\xi_{z} p & \rho h U+U_{\Omega} p
\end{array}\right]^{T}, \\
\hat{G}=J^{-1}\left[\begin{array}{lllll}
\rho V & \rho u V+\eta_{x} p & \rho v V+\eta_{y} p & \rho w V+\eta_{z} p & \rho h V+V_{\Omega} p
\end{array}\right]^{T},
\end{gathered}
$$




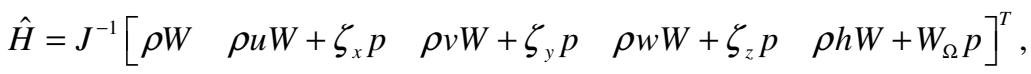

$$
\begin{aligned}
& \hat{S}=J^{-1}\left[\begin{array}{lllll}
0 & 0 & \rho \Omega^{*} w & -\rho \Omega^{*} v & 0
\end{array}\right]^{T},
\end{aligned}
$$

where the rotation axis is the $x$ axis, whose direction is from the projectile nose to the tail, and

$$
\begin{gathered}
U=\xi_{x} u+\xi_{y} v+\xi_{z} \omega-U_{\Omega}, \quad V=\eta_{x} u+\eta_{y} v+\eta_{z} \omega-V_{\Omega}, \\
W=\zeta_{x} u+\zeta_{y} v+\zeta_{z} \omega-W_{\Omega}, \\
U_{\Omega}=\xi_{y}\left(-\Omega^{*} z\right)+\xi_{z}\left(\Omega^{*} y\right), \quad V_{\Omega}=\eta_{y}\left(-\Omega^{*} z\right)+\eta_{z}\left(\Omega^{*} y\right), \\
W_{\Omega}=\zeta_{y}\left(-\Omega^{*} z\right)+\zeta_{z}\left(\Omega^{*} y\right) .
\end{gathered}
$$

The pressure $p$ and enthalpy $h$ can be related to the dependent variables by applying the ideal gas law:

$$
\begin{gathered}
p=\rho(\gamma-1)\left[e-\frac{1}{2}\left(u^{2}+v^{2}+\omega^{2}\right)\right], \\
h=e+\frac{p}{\rho} .
\end{gathered}
$$

For a numerical implementation, we used finite volume method for the spatial discretization and diagonally approximate factorization method by Pulliam and Chaussee $^{9}$ for the time integration. A more detailed explanation about the numerical technique is available in Refs. 5 and 10.

\section{Roll characteristics}

In linear roll motion, the roll moment is linearly related to fin cant angle $\delta$ and the roll rate $\Omega^{*}$ as follows

$$
C_{l}=C_{l \delta} \delta+C_{l \Omega^{*}} \Omega^{*},
$$

where $C_{l \delta}$ and $C_{l \Omega^{*}}$ are defined as roll producing moment coefficient derivative with respect to cant angle and roll damping moment coefficient derivative with respect to the nondimensionalized roll rate, respectively. Wraparound fins have nonzero roll moment even without cant angle and roll rate; therefore, Eq. (9) needs to be rewritten as

$$
C_{l}=C_{l 0}+C_{l \delta} \delta+C_{l \Omega^{*}} \Omega^{*},
$$

where $C_{I 0}$ is roll producing moment coefficient produced in the absence of roll rate.

Mikhail $^{7}$ has devised a correlation between $C_{l \delta}$ and $C_{l \Omega^{*}}$ based on the previous experimental data. Mikhail's correlation for wraparound fins is expressed as 


$$
\frac{-2 C_{l \Omega^{*}}}{C_{l \delta}\left(y_{c} / d\right)(l / h)^{m}}=2.15,
$$

where $y_{c}$ is the distance between the projectile roll axis and the area center of a wraparound fin, and $1 / \mathrm{h}$ is the ratio of the curve length of the wraparound fin to the distance between the fin tip and body surface. The exponent $\mathrm{m}$ varies with $M_{\infty}$ as

$$
m=0.1\left(1+M_{\infty}+\frac{2}{3} M_{\infty}^{2}\right) .
$$

This correlation will be used for comparison of the roll damping moment coefficient computed by the present Euler code.

\section{Computational model}

A standard wraparound fin projectile, designed by The Technical Cooperation Program (TTCP), was used as the basic configuration for the computation. TTCP standard configuration, which only has the geometry dimension and experimental data to compare the roll moment coefficient of the wraparound fin, has been widely used for several decades. Figure 1 shows the geometry of the TTCP standard configuration. All dimensions shown in Fig. 1 are expressed in units of the calibers ( 1 caliber $=10.16 \mathrm{~cm}$ ). TTCP standard configuration has fins with symmetric leading and trailing edge bevels. The angle between the root and tip chord cross section is $45 \mathrm{deg}$. The detailed fin geometry is shown in Fig. 1(b).

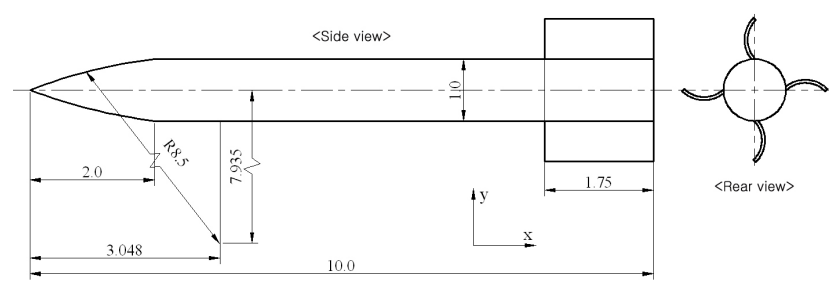

(a) Overall Geometry

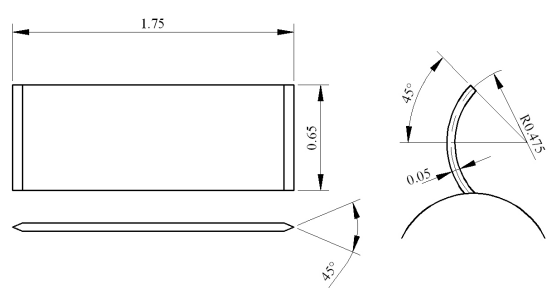

(b) Fin geometry

Fig. 1. Geometry for the TTCP standard configuration. 
The roll moments for the TTCP standard configuration were experimentally obtained from wind tunnel and free flight tests conducted at various sites. Wind tunnel tests were conducted by McDonnell Douglas Aerophysics wind tunnel, the Arnold Engineering Development Center (AEDC) and NASA Langley Research Center. The TTCP standard specifications were used for the wind tunnel experiments. It is noted that the TTCP standard configuration had boundary layer trips on the body and the fin leading edges ${ }^{1,6}$. The experimental data obtained from wind tunnel tests conducted at various sites showed a significant variation in the roll moments.

Free flight tests were conducted by Jet Propulsion Laboratory (JPL). The models used in experiments conducted at JPL were approximately 0.15 scale versions of the TTCP standard specifications. These models did not have boundary layer trips on the leading edges of the fins ${ }^{1,8}$. The roll moment coefficients computed by the present Euler code were compared obtained from experiments conducted by JPL, because the Euler equation cannot consider the viscous effects. Meanwhile, Edge $^{3}$ calculated the roll moments for a laminar flow with a three-dimensional full Navier-Stokes code. The computation model used by Edge had the blunt leading and trailing edges, and had the parallel root and tip chord cross sections ${ }^{3}$.

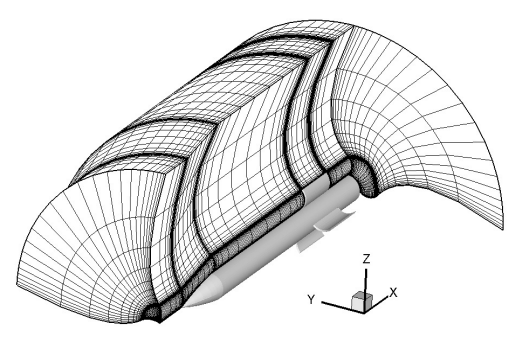

Fig. 2. Computational grid system for the TTCP standard configuration.

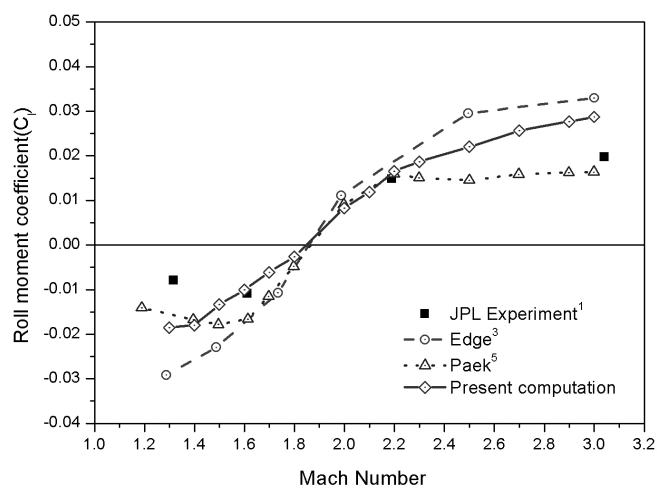

Fig. 3. Variations of the roll moment coefficients at various Mach numbers.

The grid system of the projectile model used for the aerodynamic analysis was $\mathrm{H}-\mathrm{H}$ type as shown in Figure 2 and its dimension was $85 \times 25 \times 41$. It was highly clustered near the body and fin surfaces. GRIDGEN was used to build the computational grid system.

The computational domain was taken to be the region including the concave side surface of one fin and the convex side surface of the adjacent fin as the boundaries of the domain. In general, the entire projectile with all of the fins would be needed to be solved to consider the influence of the adjacent fins. However, for an axisymmetric flowfield considered here, all fin passages can be assumed to be identical and symmetric. Then only one fin passage is needed to be solved with symmetry condition. A periodic boundary condition was used to take advantage of symmetry. This helped to reduce the number of grid cells for the computation. 


\section{Results and discussions}

Figure 3 is a graph showing the variation of the roll moment coefficients with Mach number. Computed roll moment coefficients were compared with experimental data obtained from JPL, and computationally obtained results in the Refs. 3 and 5. Figure 3 shows that the roll moment coefficients computed from the present Euler code flowfield solutions agreed well with overall trends of the experimental data. Roll moment coefficients between Mach 1.6 and 2.2 were especially well matched with experimental data. Roll reversal point, which was almost the same as the experimental data, existed at around Mach 1.8. Meanwhile, computed roll moment coefficients were somewhat different from the Edge's computational results, because there were some differences in geometry of the computational model.

As already mentioned, wraparound fins undergo rolling motion by the roll moment produced because of their cylindrical shape. From roll moment values computed at several selected roll rates, an equilibrium roll rate for the rigid fin can be determined easily. The roll damping moment coefficients for the rigid fin were computed from the roll rate versus roll moment coefficient curves at various Mach numbers. The roll damping moment coefficients for the wraparound fins are known to be difficult to obtain even experimentally, and there was little experimental data for comparison.

Hence, the roll damping moment coefficients are compared with those calculated by Mikhail's correlation of Eq. (11). $C_{l \delta}$ was needed to make use of Mikhail's correlation and was obtained by comparing the roll moment coefficient at -0.5 degree cant angle and that without cant, as shown in Table. 1. Figure 4 shows comparison of the roll damping moment coefficients calculated by Mikhail's correlation and that computed from present Euler code. The correlation gives a somewhat larger value in magnitude than the present computation, but the computed values agree well with correlation in the trend.

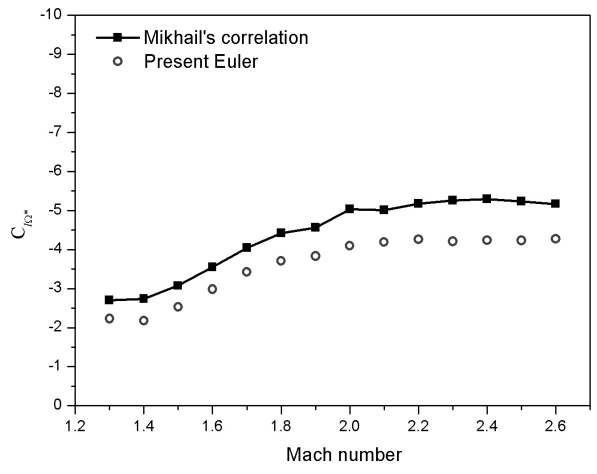

Fig. 4. Roll damping moment coefficients at various Mach numbers.
Table 1. Comparison of the roll damping moment coefficients at various Mach numbers.

\begin{tabular}{|c|c|c|c|c|c|c|}
\hline $\begin{array}{c}\text { Mach } \\
\text { No. }\end{array}$ & $C_{l 0}$ & $C_{l}^{a}$ & $C_{l}$ & $C_{l \delta}$ & $C_{l \Omega^{*}}^{b}$ & $C_{l \Omega^{*}}^{c}$ \\
\hline 1.3 & -0.0185 & -0.0446 & -0.0074 & 2.9864 & -2.2327 & -2.6985 \\
\hline 1.6 & -0.0101 & -0.0440 & 0.0049 & 3.8931 & -2.9845 & -3.5504 \\
\hline 1.9 & 0.0005 & -0.0427 & -0.0187 & 4.9473 & -3.8341 & -4.5593 \\
\hline 2.2 & 0.0166 & -0.0319 & -0.0048 & 5.5488 & -4.2610 & -5.1741 \\
\hline 2.5 & 0.0220 & -0.0264 & 0.0009 & 5.5451 & -4.2342 & -5.2382 \\
\hline
\end{tabular}

${ }^{\mathrm{a}}$ Roll moment coefficient at $0.5^{\circ}$ cant angle b $\left(C_{l}-C_{l o}\right) / \Omega^{*}$

c $-2.15 C_{l \delta}\left(y_{c} / D\right)(l / h)^{m} / 2$ 


\section{Conclusions}

The roll characteristics for a rolling wraparound fin projectile were computed in the supersonic region. The flowfield was computed by solving the Euler equation in a bodyfixed rotating coordinate frame. The roll producing moment coefficients of a wraparound fin projectile without roll rate showed favorable agreement with experimentally obtained data from JPL. The roll damping moment coefficients for the rigid fin are computed from the roll rate versus roll moment coefficient curves. The roll damping moment coefficients for the rigid fin was compared with those obtained from Mikhail's correlation based on previous experiment data. The computed roll damping moment coefficients agreed well with trend.

\section{Acknowledgments}

This work was supported by Hanwha Corporation and also partially supported by the third stage of the Brain Korea 21 Project in 2011 and WCU (World Class University) program through the National Research Foundation of Korea funded by Ministry of Education, Science and Technology (R31-2008-000-10045-0). The authors are grateful for their support.

\section{References}

1. C. W. Dahlke, Tenth Navy Sym. Aeroball. 1, 279 (1975).

2. G. L. Winchenbach, R. S. Buff, R. H. Whyte and W. H. Hathaway, J. Gui. Cont. 9, 627 (1986).

3. H. L. Edge, J. Spacecraft and Rockets, 27, 615 (1994).

4. P. Weinacht and W. Sturek, J. Spacecraft and Rockets, 33, 769 (1996).

5. S.-K. Paek and I. Lee, J. Spacecraft and Rockets, 36, 524 (1999).

6. S.-K. Paek, J.-S. Bae and I. Lee, J. Spacecraft and Rockets, 36, 53 (1999).

7. A. G. Mikhail, J. Spacecraft and Rockets, 32, 929 (1995).

8. C. W. Dahlke, U.S Army Missile Command, TR RD-77-4 (1976).

9. T. H. Pulliam and D. S. Chaussee, J. Comput. Phys. 30, 347 (1981).

10. S.-K. Paek and I. Lee, Proc. JSASS, 647 (1997). 